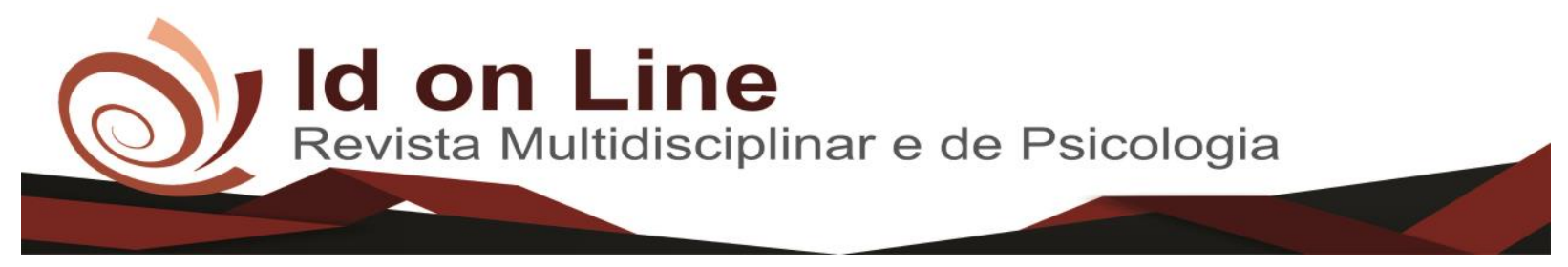

Artigo

\title{
A Responsabilidade Civil do Profissional Contábil na Cidade de Petrolina-PE
}

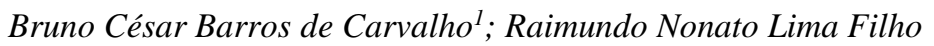

\begin{abstract}
Resumo: O profissional da contabilidade pode descumprir as normas legais de modo voluntário ou não, e ele será encarregado no desempenho das funções resultantes de sua profissão, quando não agir em harmonia com as regras relativas à sua profissão, devendo indenizar os infortúnios decorrentes de seus atos. As mudanças no novo código civil mostram uma nova visão acerca das responsabilidades desse profissional, e essas alterações expõe mais o contador no exercício da profissão, e a uma necessidade de conhecimento vasto relativo aos riscos e suas responsabilidades. O novo C.C (código civil) também trouxe um tratamento mais específico para a profissão contábil em especifico 18 artigos, do art. 1.177 ao art. 1.195. Por isso é imprescindível para que os alunos e egressos do curso de ciências contábeis, contadores e tomadores deste serviço, tenham conhecimento sobre suas atribuições e as mudanças ocorridas que abordam o ofício de suas atividades. A escolha do presente tema busca demonstrar para alunos, egressos e os profissionais contábeis, como também utilizadores deste serviço contábil, as responsabilidades civis do contador no desempenho exercício de sua função. Tendo também com a finalidade de alertar aos acadêmicos, profissionais e a sociedade das possíveis penalidades que a falta deste possa causar aos seus clientes e terceiros. $\mathrm{O}$ trabalho foi desenvolvido por meio de uma pesquisa de campo, utilizando-se um questionário perante os alunos e egressos do curso de ciências contábeis na cidade de Petrolina-PE, cuja finalidade foi analisar qual a percepção deles quanto a responsabilidade civil do profissional da contabilidade.
\end{abstract}

Palavras-chaves: Profissional de contabilidade; responsabilidade civil, código civil.

\section{The Responsibilitie of the Accounting Professional in Petrolina-PE}

\begin{abstract}
The accounting professional may be in breach of legal standards voluntarily or unintentionally, and he or she shall be responsible for carrying out the duties resulting from his or her profession, if not acting in accordance with the rules relating to his profession, and shall indemnify the misfortunes arising from his acts. The changes in the new civil code show a new vision about the responsibilities of this professional, and these changes expose more the accountant in the exercise of the profession, and a need for vast knowledge regarding risks and their responsibilities. The new civil code also brought a more specific treatment to the accounting profession in specific 18 articles, from art. 1.177 to art. 1.195. Therefore, it is essential for students and graduates of the accounting sciences course, accountants and borrowers of this service, to be aware of their attributions and the changes that have occurred that address the office of their activities. The choice of this theme seeks to demonstrate to students, graduates and accounting professionals, as well as users of this accounting service, the civil responsibilities of the accountant in performing his or her function. It is also intended to alert academics, professionals and society to the possible penalties that can not be caused to their clients and third parties. The work was developed through a field survey, using a questionnaire before the students and graduates of the course of accounting sciences in the city of Petrolina-PE, whose purpose was to analyze what their perception regarding the civil responsibility of accounting professional.
\end{abstract}

Keywords: Accounting Professional; civil liability, civil code.

${ }^{1}$ Contato: brunoelonet@gmail.com

${ }^{2}$ Doutor em Controladoria e Contabilidade (USP). Doutor em Administração (UFBA).rnlfilho@gmail.com. 


\section{Introdução}

A Contabilidade possui sua origem no início dos tempos da civilização. Surgiu com a necessidade de o homem controlar os seus bens e iniciar a prática do comércio, pois, precisava registrar de alguma maneira essas movimentações de compra e venda. Ao longo dos anos à contabilidade foi crescendo e tornando progressivamente indispensável para a gestão das empresas, em virtude que as decisões tomadas por seus diretores são baseadas quase que exclusivas nas informações geradas por esses profissionais.

A profissão "contador" é uma das profissões mais normatizadas no atual mercado de trabalho, e o contador está assumindo um novo perfil, torna-se necessário que o contador tenha um grande conhecimento da aplicabilidade da legislação que guia a sua profissão, bem como de todas as ameaças e penalidades que está sujeito no dia-a-dia no seu exercício.

Além de todo o conhecimento técnico o contador tem que observar também o código de ética, além de atentar as normas Brasileiras de contabilidade (NBC), as convenções contábeis, código civil, código penal e os princípios fundamentais de contabilidade para serem seguidos.

A responsabilidade do profissional da contabilidade vem crescendo lado a lado com a importância do contador no mercado, a responsabilidade foi duramente ampliada com o novo C,C através da Lei n. ${ }^{\circ}$ 10.406, de 10 de janeiro de 2002 (BRASIL, 2002), que entrou em vigor a partir do dia 11 de janeiro de 2003, podendo o profissional responder, pessoal e solidariamente, diante da empresa e terceiros, até mesmo com o patrimônio pessoal.

Em conformidade com a grande legislação que precisa ser observada para o desempenho da profissão contábil e também, o grande risco que este profissional e a empresa estão sujeitas, o objetivo deste estudo é analisar a percepção dos alunos e egressos do curso de ciências contábeis em Petrolina-PE acerca da responsabilidade civil do profissional contábil, pois os alunos e egressos são ou serão futuros profissionais desta área.

\section{O Comprometimento Civil do Contador}

Além do conhecimento teórico em relação as suas incumbências o contador tem que conhecer suas responsabilidades, dentre elas está a responsabilidade civil. Pois o contador pode falhar, e esses precisam ser reparados. 
No âmbito civil, lembra Gonçalves (2003, p. 33), foi consagrada "Uma regra universalmente aceita: a de que todo aquele que causa detrimento a outra pessoa é obrigado a repará-lo". Assim, a "responsabilidade" traz a ideia de garantia da restituição, significando recomposição, ressarcimento.

Segundo Oliveira (2005, p. 37), a responsabilidade civil engloba tanto a dever de reparar danos consequentes de inadimplência, de mau desempenho ou de insuficiência no cumprimento de obrigações e violação de outros direitos alheios.

É fundamental o papel desempenhado pelos contabilistas no processo de busca de soluções e interferir com informações importantes para ajudar nas definições do cotidiano, obviamente, não como responsáveis finais, pois no dizer de Gonçalves, (2007, p. 57) é interessante aperceber-se, que os contabilistas cada dia mais passam a desempenhar um papel de fundamental importância, tanto no processo gerencial/administrativo, devido ao fato de ser o profissional que tem em mãos a radiografia da empresa, como da responsabilidade no que se refere às recomendações e escolha de caminhos seguros para a empresa quando da tomada de decisões.

Silva e Brito (2004) concluem que, com as mudanças trazidas pelo novo C.C, que passou a vigorar em 11 de janeiro de 2003, aumentaram as responsabilidades do profissional de contabilidade, pois ele poderá assumir diretamente diante do terceiro, quando agir com culpa, ou solidariamente perante terceiros, quando agir com dolo, inclusive comprometendo os seus bens patrimoniais.

\section{O Novo Código Civil}

O novo C.C trouxe mudanças significativas para o profissional da área contábil, pois com o novo C.C o profissional teve seus ônus e responsabilidades ampliadas. Assim, o profissional precisa buscar meios lícitos de se proteger ou diminuir o dano.

A partir da Lei 10.406/02 que introduziu o novo código Civil, a legislação que trata notadamente da responsabilidade civil do contador passou a integrar os Art. 1.177 a 1.195, revogando a legislação presente no código Comercial.

Art. 1.177. Os assentos lançados nos livros ou fichas do preponente, por qualquer dos prepostos encarregados de sua escrituração, produzem, salvo se houver procedido de má-fé, os mesmos efeitos como se o fossem por aquele. 
Parágrafo único. No exercício de suas funções, os prepostos são pessoalmente responsáveis, perante os preponentes, pelos atos culposos; e, perante terceiros, solidariamente com o preponente, pelos atos dolosos. (BRASIL, 2002).

Dessa forma, Fiuza (2006) explica que como regra geral de responsabilidade na relação de preposição, em virtude de ato culposo que o preposto (contabilista) venha causar, ele será diretamente responsável diante do preponente e haverá responsabilidade objetiva da empresa, cabendo a esta indenizar os prejuízos causados, enquanto na ocorrência de ato doloso ocorrerá situação de solidariedade, de maneira que será exigido do preponente junto com o preposto o ressarcimento de prejuízos provocados a terceiros.

\section{O Papel do Contador}

O contador desempenha uma função importante na sociedade, seja ele um funcionário de uma empresa, ou um empresário contador, ele terá que conhecer além de suas atribuições todas as suas responsabilidades.

De acordo com Echeverria (2000, p. 88), “[...] onde houver uma empresa, haverá um contador. Seja na sua criação, ou no acompanhamento de seu desenvolvimento, a empresa obrigatoriamente contará com este profissional." Deve, pois, sempre estar bem informado e renovando seus conhecimentos através de estudos pertinentes a sua profissão e estudos relacionados às empresas.

Percebe-se que o profissional contábil tem que estar sempre no ciclo do aprendizado, pois a todo o momento surgem novidades e o contador não pode estar defasado.

Para Cosenza (2001), aqueles profissionais que não procurarem aumentar seus conhecimentos, bem como não estiverem preocupados em se reciclar e atualizar tornar-se-ão secundários, dispensáveis, e acabarão ficando numa espécie de limbo organizacional. O mercado demandará profissionais que tenham a capacidade de perceber as mudanças no ambiente mundial e consigam saber seus limites de atuação.

Segundo Fabretti (2014), o contador é o profissional cujo oficio está ligado à gestão de controle do patrimônio das pessoas, entidades e empresas, o seu comportamento ético é de fundamental interesse para particularidades do Fisco.

É interessante falar que o contador atual desempenha inúmeras atribuições, e todas as atribuições possuem os seus riscos. 
Também segundo Fabretti (2014), em virtude da natureza do seu oficio o contabilista deve estar atento aos fatos para evitar o cometimento de falhas, e como não se bastasse muitas vezes lhe é solicitado práticas de atos ilícitos com intenção de benefícios, que fica caracterizado crime fiscal, trazendo penalidades tanto para o cliente quanto ao profissional.

O profissional Contábil vem assumindo uma função que oferece não só a empresário, mas à sociedade vários benefícios, tais como: a minoração dos riscos na escolha dos investimentos e eventuais aplicações, a destinação dos recursos somada à indiscutível capacidade de aprender a lidar com mudanças mercadológicas e com as ideias de melhorias, conforme posicionamento de Marion (2005, p. 33).

Devido a isso, a importância da profissão contábil não somente a fins gerenciais.

\section{Metodologia}

Para Severino (2007), as questões devem ser relevantes ao objeto e claramente desenvolvidas, assim serem bem compreendidas pelos pesquisados. As questões devem ser objetivas, de modo motivar respostas igualmente concretas, assim evitando levantamento de dúvidas, ambiguidades e respostas concisas. Em relação das questões podem ser abertas ou fechadas.

Nesse caso, a metodologia utilizada foi uma pesquisa de campo, utilizando-se um questionário perante os alunos e egressos do curso de ciências contábeis na cidade de PetrolinaPE, cuja finalidade foi analisar qual a percepção deles acerca da responsabilidade civil do profissional contábil. A população conforme Diehl e Tatim (2006, p.63) "pode ser formada por pessoas, famílias, empresas ou qualquer outro tipo de elemento", enquanto a amostra é uma "parcela desta população convenientemente selecionada". Desse modo, a pesquisa aplicada com os alunos e egressos do curso de ciências contábeis para que seja possível obter uma percepção em relação a responsabilidades civil do contador. O universo de pesquisa é de aproximadamente 600 pessoas, e a amostra mínima necessária é de 90 pessoas.

Segundo Lakatos e Marconi (2007), os estudos qualitativos podem retratar a dificuldade de certo problema e a influência de certos fatores.

A pesquisa foi por dois métodos, pesquisa presencial (entrevista) e pesquisa via questionário online. Foram realizadas entrevistas que trouxe consigo características qualitativas e quantitativas, para que se tenha uma percepção de como os alunos e egressos estão à parte do novo C.C. 


\section{Análise de Dados}

Após a coleta, procede-se a análise descritiva dos dados, que consiste basicamente em buscar elementos que reforcem as premissas iniciais e indiquem alguma conclusão. Foi utilizada como método a abordagem qualitativa, por essa técnica demonstrar em maioria ser mais adequada para se obter e interpretar as informações pertinentes à pesquisa, pois esta abordagem promove uma postura crítica acerca do objeto que está sendo estudado, de modo interativo, ao confrontar as informações quantificadas pelos resultados do questionário, para com a conjuntura da situação a ser analisada.

Em relação à responsabilidade civil, foram enumeradas algumas questões para ajudar na percepção sobre as responsabilidades aplicáveis ao profissional da contabilidade, ou seja, o novo posicionamento do profissional contábil a partir do novo C.C.

O novo C.C entrou em vigência a partir de 11/01/2003, e trouxe uma ampla visão da conduta de um contabilista, agora se tem conhecimento sobre os quesitos para saber se uma empresa atende aos requisitos e formalidades legais de uma escrituração contábil, independente delas se forem de pericias de natureza trabalhista, tributária ou civil, além de exigir que o contador possua registro no CRC (Conselho Regional de Contabilidade).

Caso o mesmo não o tenha pode desqualificar toda a escrituração do empresário. Todos esperam de seu contador integridade e boa conduta profissional nos seus serviços, além de agir sempre em conformidade com o código de Ética Profissional. Ela não se restringe apenas ao órgão representante da classe (CRC), é muito mais abrangente. Sendo assim, as regras são impostas aos profissionais para melhor entender o funcionamento do processo contábil.

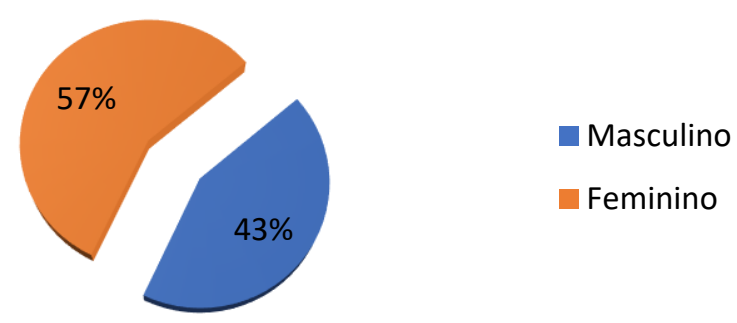

Gráfico 1: Sexo dos entrevistados

Fonte: Dados da pesquisa

No gráfico 1 foi apresentado o sexo dos entrevistados, na qual $43 \%$ dos entrevistados são do sexo masculino e $57 \%$ são do sexo feminino. 


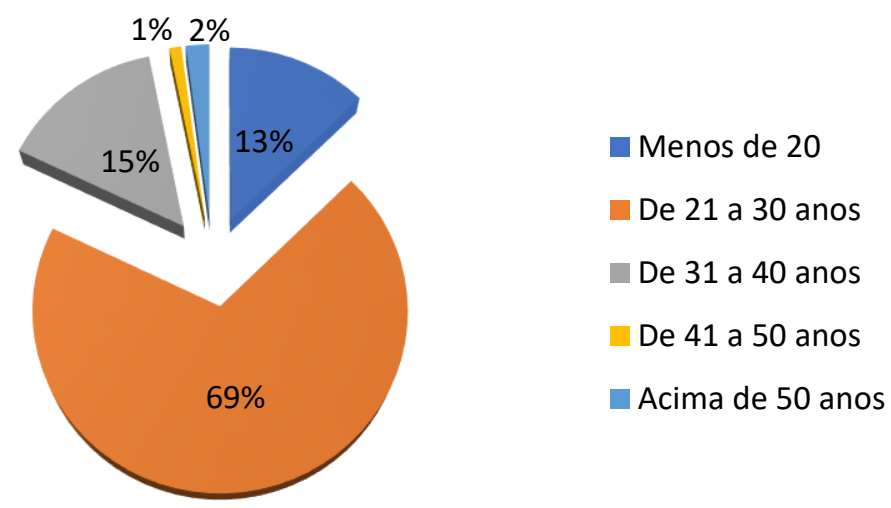

Gráfico 2: Faixa de idade Fonte: Dados da pesquisa

Já no gráfico 2, os entrevistados foram questionados sobre a idade, dentre as opções estavam menos de 20 ,entre 21 a 30 anos, 31 a 40 anos, 41 a 50 anos e acima de 50 anos, numa escala progressiva, dos entrevistados $13 \%$ tem menos de 20 anos, a maior parcela representando 69\% compreendem a idade de 21 a 30 anos, outros $15 \%$ de 31 a 40 anos, é compreendida por $1 \%$ os de idades entre 41 a 50 anos e acima de 50 anos $2 \%$.

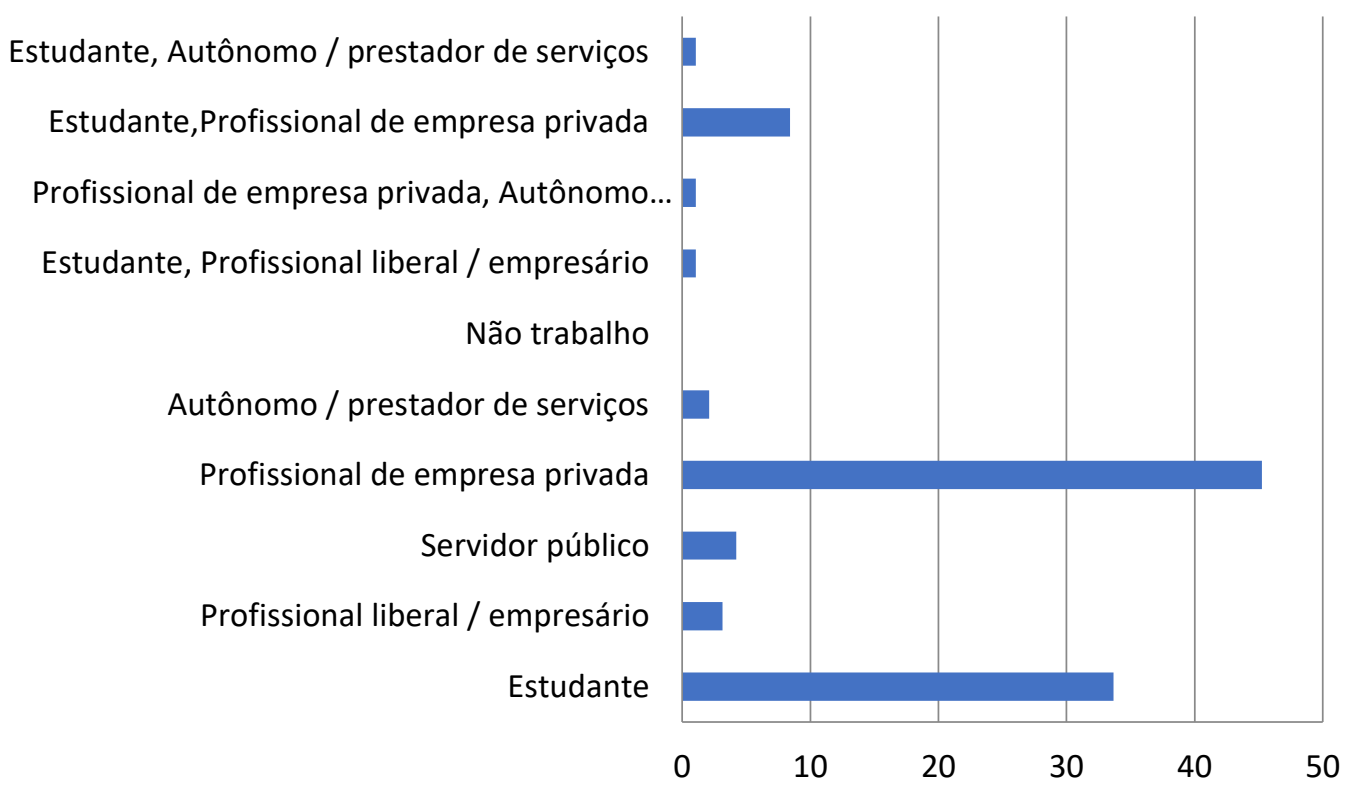

Gráfico 3: Ocupação principal Fonte: Dados da pesquisa

No gráfico 3, os entrevistados foram questionados sobre sua ocupação principal, onde dos entrevistados cerca de $45 \%$ é profissional de empresa priva, aproximadamente $34 \%$ somente estuda, $8 \%$ estuda e trabalha em empresa privada, são servidores públicos cerca de $4 \%$ dos 
entrevistados, e profissional liberal ou empresário compõe apenas de 3\%, autônomos com cerca de $2 \%$.

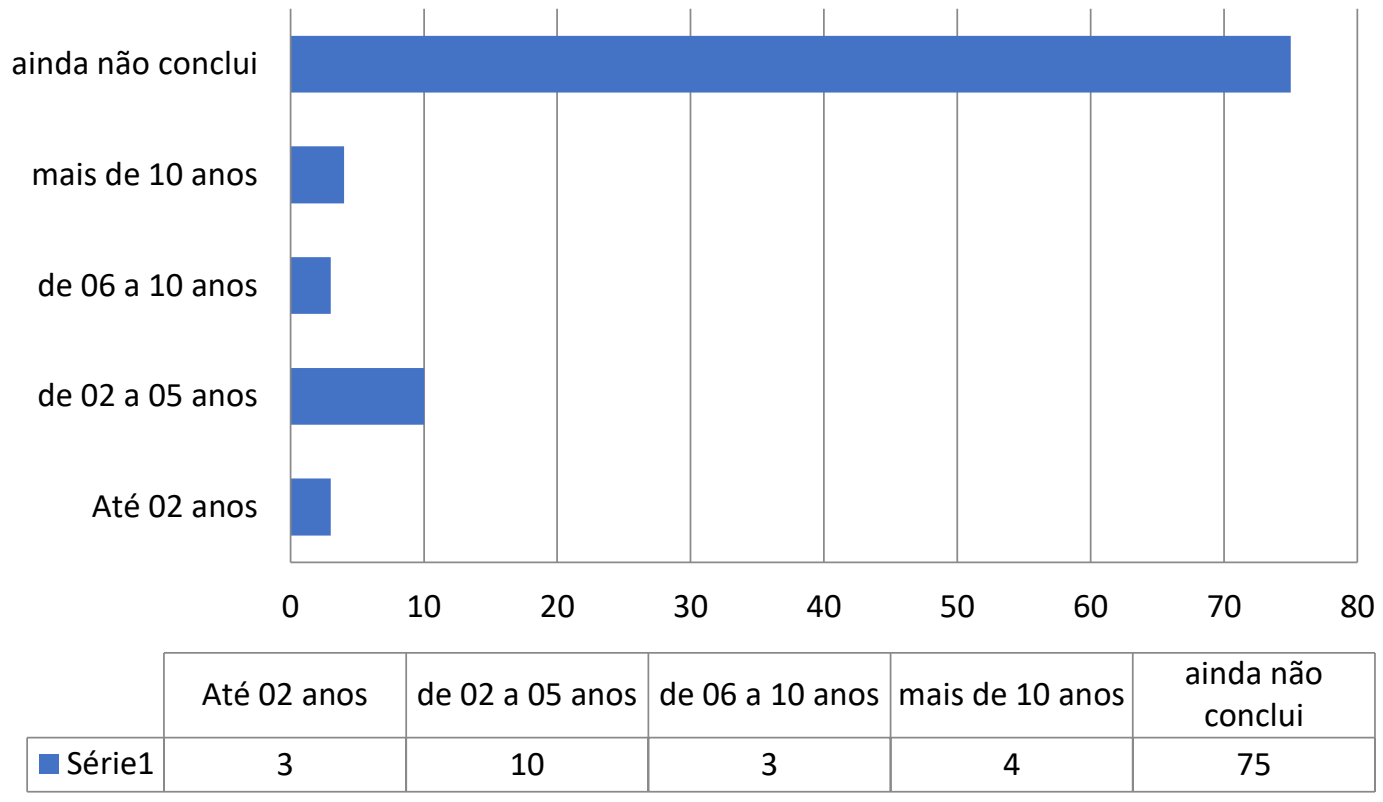

Gráfico 4: Há quanto tempo concluiu a faculdade?

Fonte: Dados da pesquisa

No gráfico 4, demostra que cerca de aproximadamente $79 \%$ ainda não concluiu a faculdade, $11 \%$ já concluiu no período de 02 a 05 anos, somente $4 \%$ já concluiu com o tempo superior a 10 anos, e com as mesmas porcentagens até 02 anos e de 06 a 10 anos com aproximadamente $3 \%$.

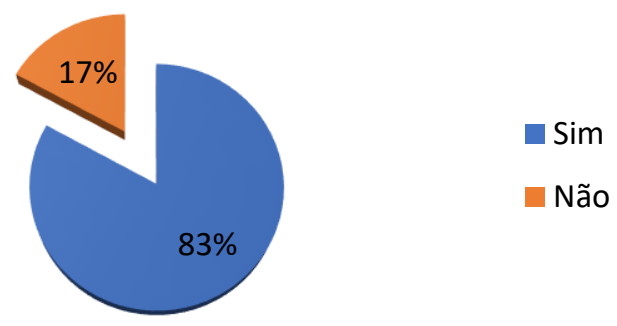

Gráfico 5: Você já escutou ou escuta os professores da sua instituição falando sobre as responsabilidades do profissional contábil?

Fonte: Dados da pesquisa 
Dando seguimento o gráfico 5, foi indagado aos entrevistados se os mesmos escutam ou já tinham escutado os professores da sua instituição falando sobre as responsabilidades do profissional contábil, surpreendentemente cerca de $83 \%$ diz já ter escutado ou escuta os mestres comentarem a temática.

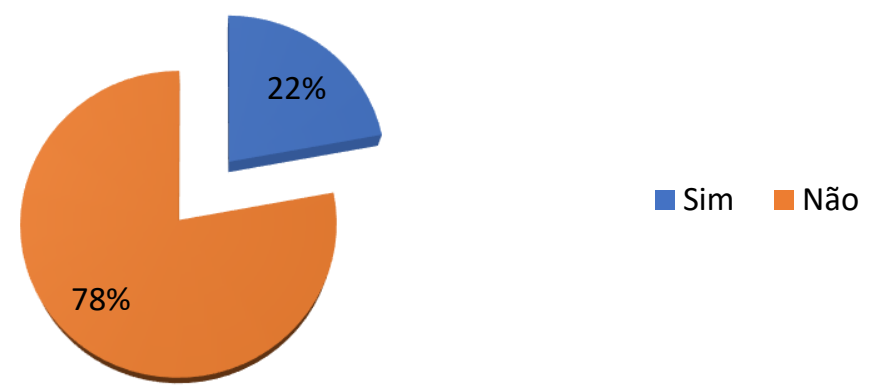

Gráfico 6: Alguma vez sofreu fiscalização?

Fonte: Dados da pesquisa

No gráfico 6 , ficou claro que $78 \%$ dos entrevistados nunca sofreu fiscalização e apenas $22 \%$ já sofreu.

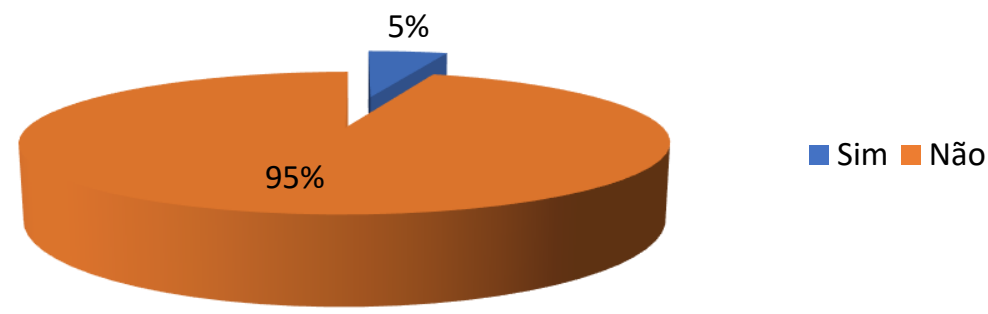

Gráfico 7: Alguma vez já sofreu alguma penalidade por ter atendido algum pedido de cliente o qual gerou infrações?

Fonte: Dados da pesquisa

Como mostra o gráfico 7 , ao ser questionado sobre sofrimento penalidade por ter atendido algum pedido de cliente, como boa parte dos entrevistados nunca sofreu fiscalização ajudou significativamente esse gráfico demostrar que $95 \%$ dos entrevistados jamais sofre alguma penalidade devido a pedidos de clientes e apenas $5 \%$ já sofreu. 


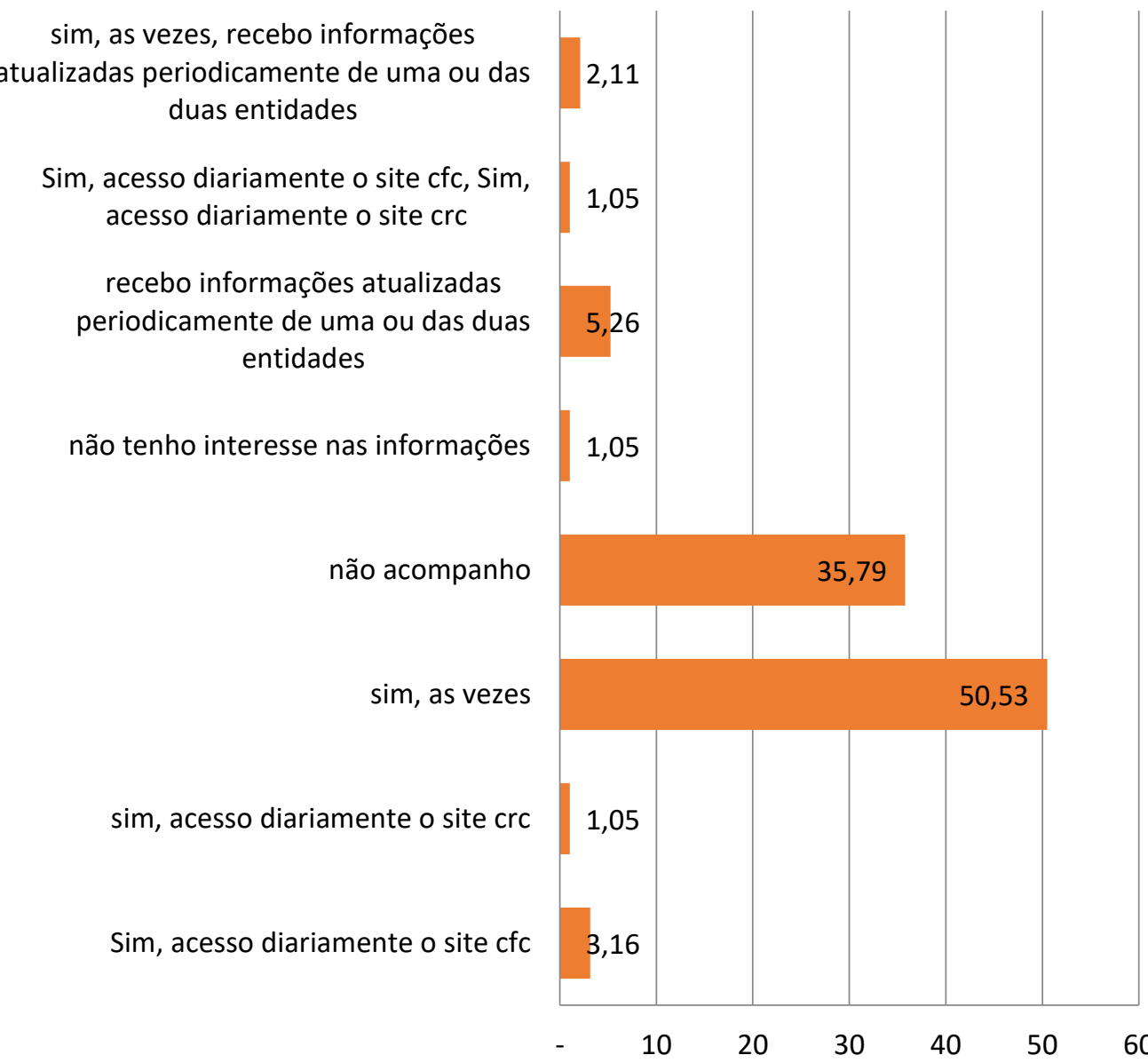

Gráfico 8: Você tem acompanhado as informações e acontecimentos inerentes a classe contábil, emitidas pelo CFC (conselho Federal de contabilidade) e CRC (conselho regional de Contabilidade)?

Fonte: Dados da pesquisa

No gráfico 8 , foi indagado ao entrevistado se ele tem acompanhado as informações e acontecimentos Inerentes a classe contábil, emitidas pelo CFC (conselho Federal de contabilidade) e CRC (conselho regional de Contabilidade), mostrando uma informação importante pois o aluno ou egresso do curso de ciências contábeis precisa estar sempre atualizado, e os conselhos servem também com essa ferramenta, cerca de $50 \%$ tem acompanhado, e aproximadamente $36 \%$ não acompanha, e os demais entrevistados acompanham um ou os dois conselhos e outros recebem as informações periodicamente. 


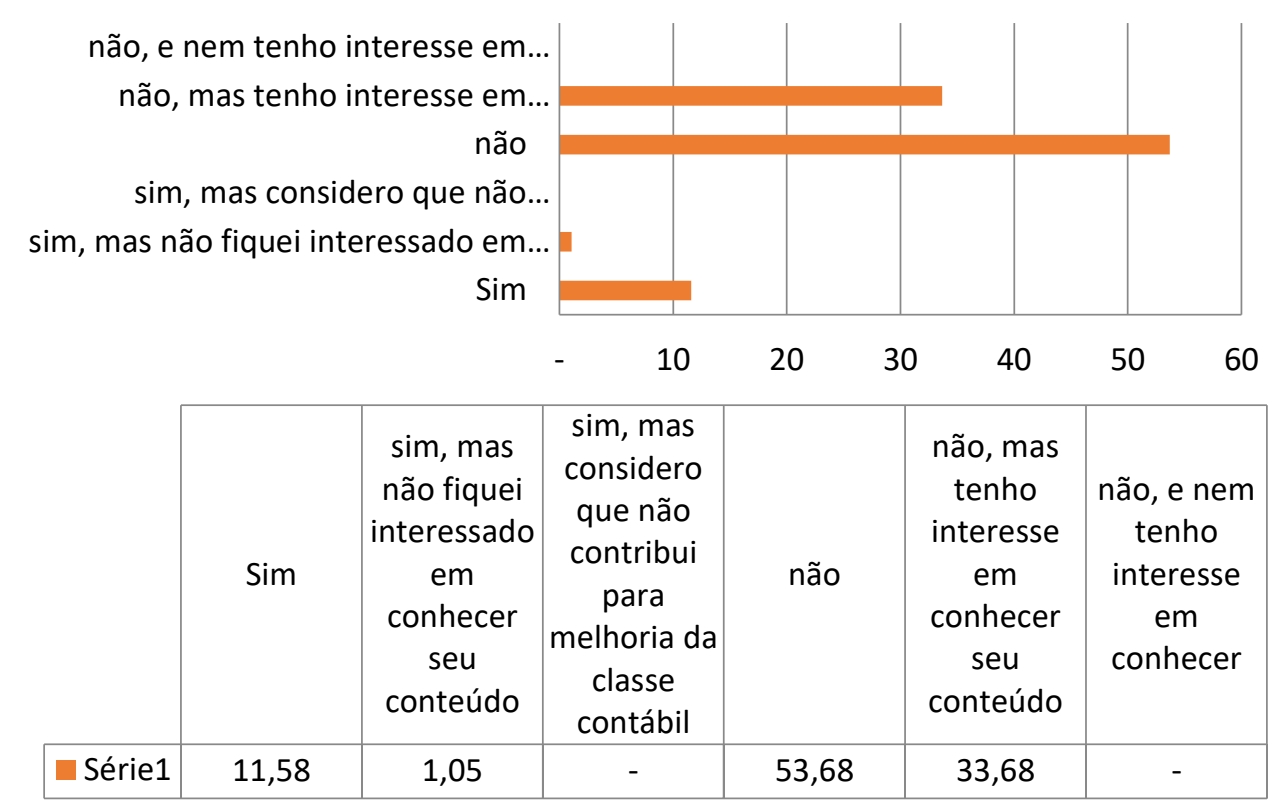

Gráfico 9: Você sabe o que foi aprovado através da resolução 803/96 do CFC? Fonte: Dados da pesquisa

Com a aprovação da Resolução do Conselho Federal de Contabilidade, foi promulgado o código de ética do contabilista, no gráfico 9 foi questionado aos entrevistados sobre o conhecimento dos mesmos sobre esse código de ética.

E para surpresa pouco mais de 53\% não sabe o que foi aprovado através dessa resolução, $34 \%$ não conhece, mas tem interesse em conhecer, apenas $12 \%$ sabe o que foi aprovado na resolução 803/96 do CFC e apenas 1\% afirmou saber, mas não ter interesse em conhecer o conteúdo.

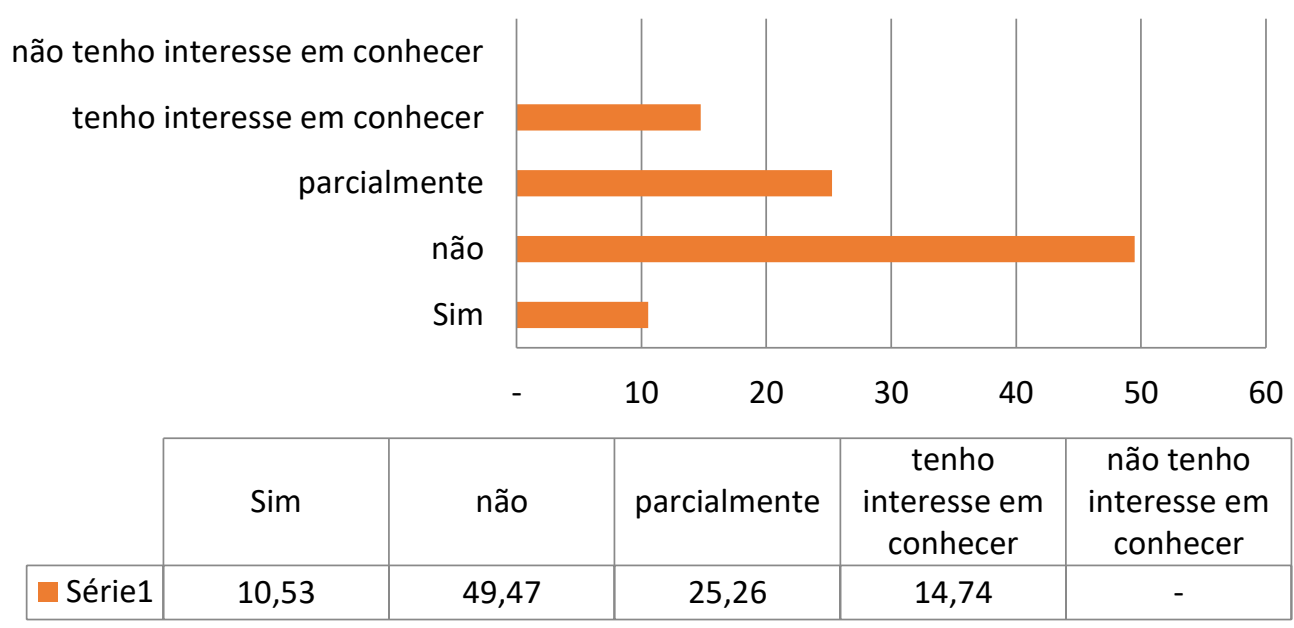

Gráfico 10: Conhece as alterações do novo código civil que foi vigorado em 11 de janeiro de 2003?

Fonte: Dados da pesquisa 
No gráfico 10, foi proposto aos entrevistados sobre as alterações que ocorreram no código Civil em 11/01/2003, e cerca de $11 \%$ conhecem as alterações do novo C.C e aproximadamente $49 \%$ não conhece, considerado esse resultado como um alerta, pois essas alterações são de extrema importância sobre as responsabilidades do profissional contábil, cerca de $25 \%$ conhece parcialmente essas alterações do novo C.C (código civil) e cerca de $15 \%$ tem interesse em conhecer essas alterações.

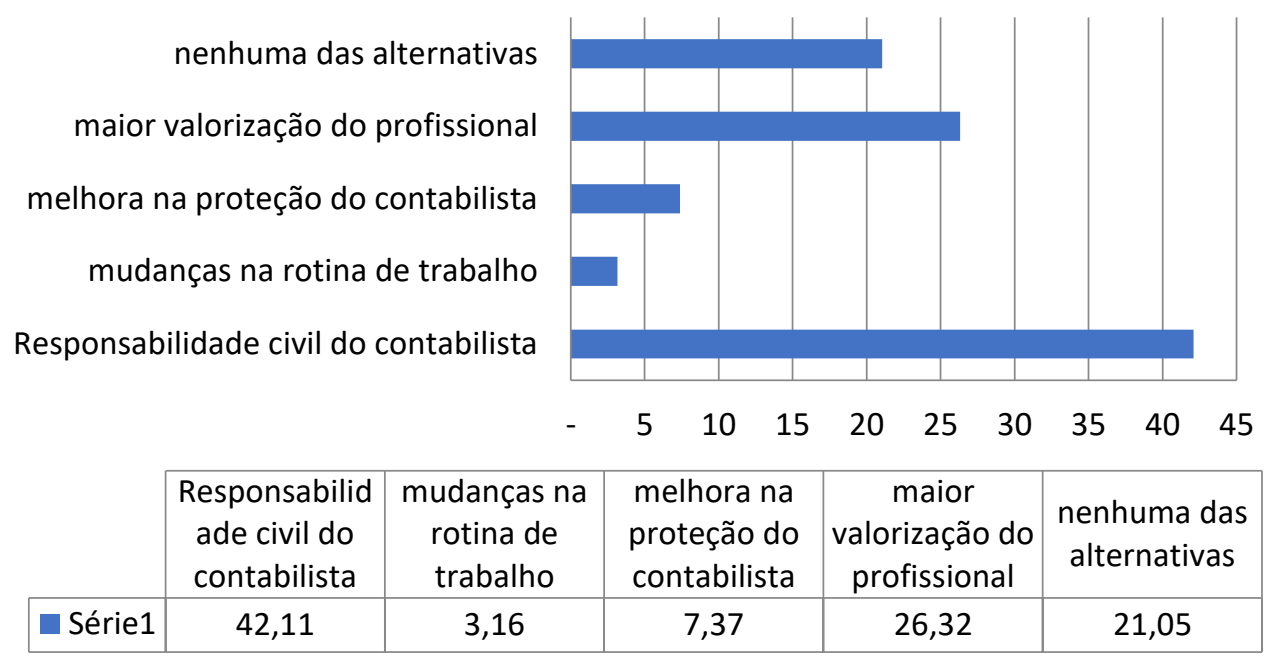

Gráfico 11: Assinale as mudanças consideradas relevantes para a classe contábil com o advento do novo código civil de Lei 10.406 de 2002, Artigo 1.177. Fonte: Dados da pesquisa

Questionados sobre as mudanças relevantes que ocorreram no código civil, os entrevistados afirmaram em $42 \%$ que a maior alteração é a responsabilidade civil dos profissionais da área contábil, em segundo lugar $26 \%$ que se trata da maior valorização do profissional, $21 \%$ dos entrevistados afirmaram que não se trata de nenhuma das alternativas disponíveis, $7 \%$ acredita que se trata da melhora na proteção do contabilista e $4 \%$ acredita que as mudanças foram na rotina de trabalho. 


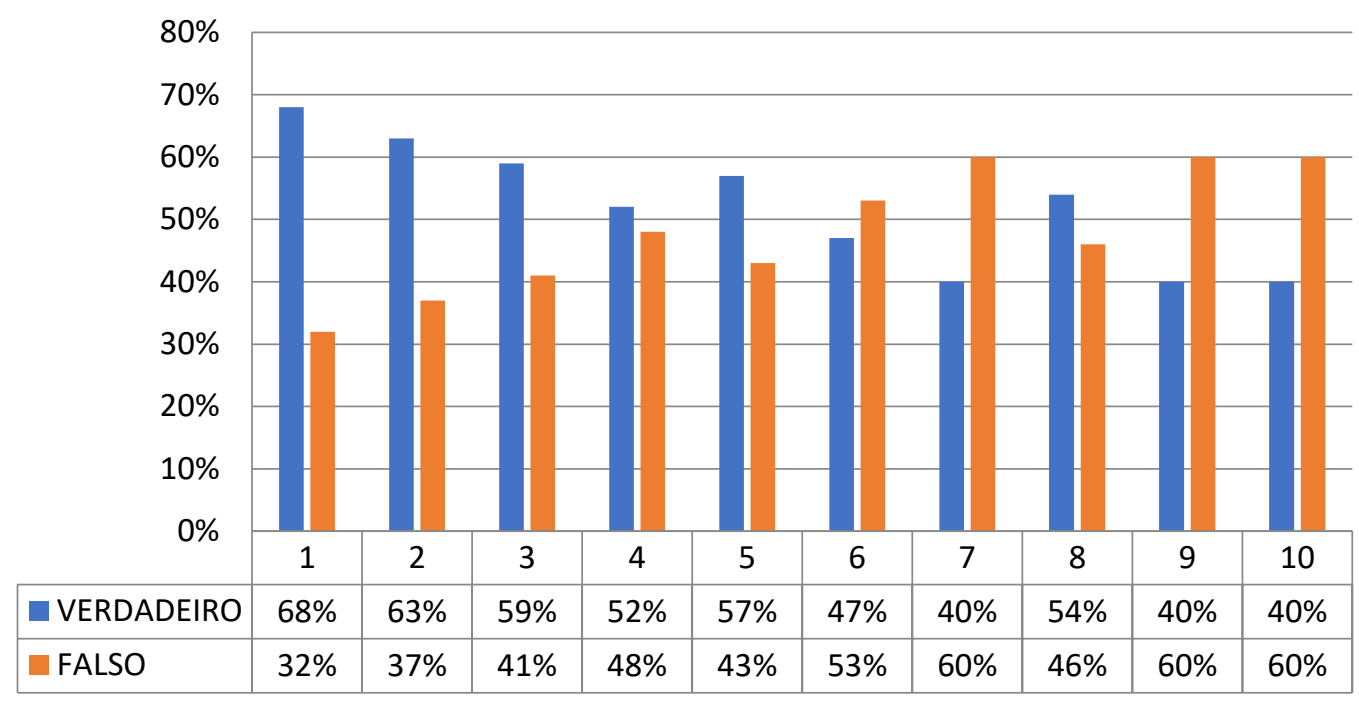

Gráfico 12:Questionário verdadeiro ou falso, sobre a responsabilidade civil do profissional contábil.

Fonte: Dados da pesquisa

No gráfico 12, foi realizada uma pequena avalição de verdadeiro e falso, para medir o nível de conhecimento acerca da responsabilidade civil dos alunos e egressos do curso de ciências contábeis.

1-No exercício de suas funções, os prepostos são pessoalmente responsáveis perante os preponentes pelos atos culposos; e perante terceiros, solidariamente com os preponentes, pelos atos dolosos.

Dos entrevistados aproximadamente $68 \%$ assinalaram corretamente a questão e $32 \%$ incorretamente.

2-Para que haja o dever de indenizar decorrente da responsabilidade civil, não é necessário que haja nexo entre a condutado agente e o prejuízo suportado pela vítima, ou seja, a conduta e o dano devem não estar intimamente ligados.

Dos entrevistados aproximadamente $63 \%$ assinalaram incorretamente a questão e $37 \%$ corretamente.

3-No exercício de suas funções, os prepostos não são pessoalmente responsáveis, perante os preponentes, pelos atos culposos; e, perante terceiros, solidariamente com o preponente, pelos atos dolosos, mesmo estando autorizados por escrito.

Dos entrevistados aproximadamente 59\% assinalaram corretamente a questão e $41 \%$ incorretamente. 
4-O contador não pode ter o seu patrimônio pessoal confiscado, para que sejam ressarcidos os possíveis danos causados por sua conduta inadequada e sim do seu empregador ou cliente.

Dos entrevistados aproximadamente $48 \%$ assinalaram corretamente a questão e $52 \%$ incorretamente.

5-Os preponentes são responsáveis pelos atos de quaisquer prepostos, praticados nos seus estabelecimentos e relativos à atividade da empresa, ainda que não autorizados por escrito.

Dos entrevistados aproximadamente $57 \%$ assinalaram corretamente a questão e $43 \%$ incorretamente.

6-O contador é totalmente responsável pelo cometimento de atos contrários ao direito ou por eventuais erros e fraudes no exercício de sua função. O seu empregador ou cliente não responde pelas consequências geradas.

Dos entrevistados aproximadamente 57\% assinalaram incorretamente a questão e $43 \%$ corretamente.

7-Quando tais atos forem praticados fora do estabelecimento, somente obrigarão o preponente nos limites dos poderes conferidos por escrito.

Dos entrevistados aproximadamente $60 \%$ assinalaram incorretamente a questão e $40 \%$ corretamente.

8-A responsabilidade civil consiste na obrigação do agente causador do dano em reparar o prejuízo causado a outrem, somente por ato próprio e jamais por alguém que dele dependa.

Dos entrevistados aproximadamente $46 \%$ assinalaram corretamente a questão e $53 \%$ incorretamente.

9-As espécies da responsabilidade civil são divididas em duas, a objetiva e subjetiva.

Dos entrevistados aproximadamente $40 \%$ assinalaram corretamente a questão e $60 \%$ incorretamente.

10-Os erros de responsabilidade do profissional contábil não tem prazo para prescrever, em caso de prejuízo, caberá ao contador reparar os danos causados a qualquer tempo.

Dos entrevistados aproximadamente $40 \%$ assinalaram incorretamente a questão e $60 \%$ corretamente. 


\section{Considerações Finais}

O trabalho objetivou analisar a percepção dos alunos e egressos do curso de ciências contábeis acerca da responsabilidade civil do profissional contábil em face da vigência do novo C.C brasileiro. Dessa forma, o conteúdo embasou-se em um referencial teórico que evidenciou a responsabilidade e a importância da atualização do profissional, pois esse profissional é de fundamental importância no processo de busca de soluções e na tomada de decisões, sendo como responsáveis finais ou não.

Assim, para atingir o objetivo, utilizou-se uma amostra de 95 alunos e egressos do curso, aplicando um questionário para cada entrevistado, em seguida, com dados obtidos, adotou-se analise das respostas, análise mediante gráficos. Com isso, pode-se perceber que dentre os 95 respondentes, 54 eram do gênero feminino e 41 masculinos, demostrando juntamente o grande crescimento do público feminino na área contábil. Um pouco acima da média os entrevistados possuem entre 21 a 30 anos, onde boa parte ainda não concluiu o curso do ensino superior, 79 questionados já escutaram ou escutam dos professores sobre as responsabilidades do profissional contábil.

Ao investigar se já tinha sofrido fiscalização, não houve surpresa, pois boa parte ainda não terminou a curso superior, e consequentemente 90 dos entrevistados, jamais sofreu alguma penalidade. Constatou-se também que mais de 50\% dos alunos e egressos acompanham as informações dos concelhos de contabilidade, sendo o regional ou federal, mais mostra que quase $50 \%$ não conhecem as novas alterações do novo C.C, em seguida foi aplicada uma questão com dez alternativas para avaliação com o método de verdadeiro ou falso, onde demostrou devido a esse pouco conhecimento das alterações no C.C (código civil) o desempenho foi um pouco abaixo da média.

Nesse ínterim, como proposta para futuras pesquisas, propõe-se quanto a metodologia expandir o tamanho da amostra, considerando como população também os profissionais da cidade de Petrolina-PE, podendo até incluir outro Estado para verificar se os resultados se assemelham bem como a utilização de análise qualitativa, permitindo o uso de outros instrumentos de análise de dados, recomenda-se novas investigações, por exemplo, aplicar uma auto avaliação aos alunos, egressos e contadores, pois quando um indivíduo se auto avalia, ele desenvolve o senso de responsabilidade e o espírito crítico. 


\section{Referências}

BRASIL. LEI No 10.406, DE 10 DE JANEIRO DE 2002. Institui o Código Civil. Brasília,DF,jan 2002.

Disponível em:http://www.planalto.gov.br/ccivil_03/leis/2002/110406.htm:Acesso em 18 ago. 2018.

COSENZA, J. P. Perspectivas para a profissão contábil num mundo globalizado: um estudo a partir da experiência brasileira. Revista Brasileira de Contabilidade, Brasília, $n$. 130, p. 43-61, jul./ago. 2001.

DIEHL, Astor Antônio; TATIM, Denise Carvalho. Pesquisa em Ciências Sociais Aplicadas: Métodos e técnicas. 2. ed. São Paulo: Pertince Hall, 2006.

ECHEVERRIA, I. O profissional da contabilidade e o mercado de trabalho. Revista Brasileira de Contabilidade, Brasília, n. 122, p. 87-91, mar/abr. 2000.

FABRETTI, Láudio Camargo; Contabilidade Tributária. 14. ed. São Paulo: Atlas S.A, 2014.

FIUZA, Ricardo. Novo Código Civil Comentado. 5. ed. São Paulo: Saraiva, 2006

GONÇALVES, Carlos Roberto. Comentários ao código civil, Volume XI, São Paulo: Saraiva, 2003.

GONÇALVES, Viviane Greche. A importância das sanções na atuação profissional dos contadores. Revista Brasileira de Contabilidade, Brasília, n. 166, p. 57-71, jul./ago. 2007.

LAKATOS, Eva Maria; MARCONI, Marina de Andrade. Metodologia do trabalho científico. 6. ed. São Paulo: Atlas, 2007.

MARION, José Carlos. Contabilidade Empresarial. São Paulo: Atlas, 2005.

OLIVEIRA, C. M. Responsabilidade civil e penal do profissional de contabilidade. São Paulo: IOB-Thomson, 2005.

SEVERINO, Antônio Joaquim. Metodologia do trabalho Científico. $23^{\circ}$. ed. rev. e atual. São Paulo: Cortez, 2007.

SILVA, Lázaro Rosa da; BRITO, Valmir Bezerra de. O Novo Código Civil para Contadores. São Paulo: IOB-Thomson, 2004.

Como citar este artigo (Formato ABNT):

CARVALHO, Bruno Cesar Barros de; LIMA FILHO, Raimundo Nonato. A Responsabilidade Civil do Profissional Contábil na Cidade de Petrolina-PE. Id on Line Rev.Mult. Psic., 2019, vol.13, n.43, p. 506521. ISSN: 1981-1179.

Recebido: 05/12/2018; Aceito: 07/12/2018 